\title{
A comparative study of vaginal misoprostol, dinoprostone gel, foley catheter, extra amniotic saline infusion along with vaginal misoprostol for induction of labor at term
}

\author{
Ektha M. Shetty ${ }^{1 *}$, Asha Neravi ${ }^{2}$
}

\begin{abstract}
${ }^{1}$ Department of Obstetrics and Gynecology, Father Muller Medical College Hospital, Kankanady, Mangalore, Karnataka, India

${ }^{2}$ Department of Obstetrics and Gynecology, SDM College of Medical Sciences and Hospital, Dharwad, Karnataka, India
\end{abstract}

Received: 19 June 2020

Revised: 15 August 2020

Accepted: 17 August 2020

\section{*Correspondence:}

Dr. Ektha M. Shetty,

E-mail: ekthamshetty@fathermuller.in

Copyright: (c) the author(s), publisher and licensee Medip Academy. This is an open-access article distributed under the terms of the Creative Commons Attribution Non-Commercial License, which permits unrestricted non-commercial use, distribution, and reproduction in any medium, provided the original work is properly cited.

\section{ABSTRACT}

Background: Objective of this study was to study the effect of vaginal misoprostol, dinoprostone gel, foley catheter, extra amniotic saline infusion along with vaginal misoprostol for induction of labor at term on maternal and fetal outcome.

Methods: A one-year prospective observational study was conducted in the department of obstetrics and gynecology, SDM College of Medical Science and Hospital, Dharwad. Totally 100 postdated primigravida women with singleton gestation, vertex presentation and intact membrane who were induced with any four methods of induction 1) Tab. misoprostol $25 \mu \mathrm{g}$ vaginally, 2) Intracervical dinoprostone gel, 3) Foley catheter and 4) Extra amniotic saline infusion along with tab. misoprostol $25 \mu \mathrm{g}$ vaginally with 25 patients selected in each group, by random allocation technique and included in the study. Outcome measures analysed were the demographic profile, bishop score, induction to delivery interval, mode of delivery, maternal and fetal complications. Statistical analysis was done using SPSS 17 software.

Results: Mean induction delivery interval was significant between PGE1 versus foley group ( $\mathrm{p}=0.0034)$. In this study, $60 \%$ patients in dinoprostone group had Vaginal delivery and $72 \%$ in the EASI + misoprostol group underwent cesarean section $(\mathrm{p}=0.0372)$. NICU admission was maximum with EASI + vaginal misoprostol group and minimum with vaginal misoprostol alone.

Conclusions: The groups were comparable with respect to maternal age, bishop score and fetal weight. The vaginal misoprostol group had shortest induction delivery interval. The maximum number of patients in dinoprostone gel group underwent vaginal delivery with a highest cesarean section and NICU admission with the EASI + misoprostol group.

Keywords: Bishop score, Dinoprostone gel, Extra amniotic saline infusion, Foley catheter, Induction of labor, Misoprostol

\section{INTRODUCTION}

The history of labor induction dates back to Hippocrates' description of cervical canal dilation by mammary stimulation and mechanical techniques. ${ }^{1}$ Induction of Labor is the stimulation of contraction before the spontaneous labor onset, with or without ruptured membranes. ${ }^{2}$ During the second century AD, soranus 
used a combination of procedures to induce labor, including artificial rupture of the membranes (ARM). Other methods of labor induction had been introduced during this period. In the $17^{\text {th }}$ century, mechanical methods to induce labor came into more common use. In 1810, James was the first in the United States to use amniotomy to induce premature labor. ${ }^{3}$ Until $20^{\text {th }}$ century amniotomy and other mechanical methods remained the techniques of labor induction. In 1943, page suggested that the pituitary extract oxytocin be in the form of an intravenous infusion, and in 1955 synthetic oxytocin has been in use. ${ }^{4}$ In 1968, Karim and colleagues were the first to report the use of prostaglandins for induction of labor. ${ }^{5}$ Since then, prostaglandins, in different varieties and forms of administration, became a common method of labor induction. ${ }^{6}$ Both mechanical dilator and pharmacological procedures have been found successful in Induction of labor. Misoprostol, a synthetic PGE1 analogue, safely and effectively ripens the cervix and induces labor in patients with unfavourable cervix. ${ }^{7}$ Intravaginal doses of 25-50 $\mu \mathrm{g}$ have shown to shorten the induction to vaginal delivery interval and to lower the caesarean delivery rate. Dinoprostone (PGE2) is the prostaglandin most commonly employed in obstetrics. This prostaglandin plays an important role in the cervical ripening process and in initiating and maintaining labor. The intracervical route has been used in around two thirds of reported clinical trials. The commercial dinoprostone gel contains $0.5 \mathrm{mg}$ of dinoprostone is available in a prefilled applicator. Active labor and vaginal delivery are more likely to occur within this 12 hour period, reducing the need for oxytocin infusion.

The commonly used mechanical method of induction includes the foley catheter and extra amniotic saline infusion. For a single balloon catheter, a number 18 foley is introduced under sterile technique in the intracervical canal past the internal OS. The bulb is inflated with 30 to $60 \mathrm{ml}$ of water. The catheter is left in place until either it falls out spontaneously or 24 hours have elapsed. Foley catheters have shown to be efficacious with a shorter induction to-delivery interval than prostaglandin in patients with unfavourable cervix. Both agents have similar caesarean section rates, but foley catheter may require increased need for oxytocin stimulation and there is more tachysystole with prostaglandin. ${ }^{8}$ Extra amniotic saline infusion (EASI) involves infusion of isotonic fluid into extra-amniotic space. It is an effective method of cervical ripening than labor prostaglandin, however, it does not improve the outcome of induction when compared with Foley catheter alone. A 2001 Cochrane review reported mechanical methods to have less tachysystole with fetal heart changes than prostaglandin's but no difference in caesarean section rates. ${ }^{8}$

A 2009 RCT of 330 nulliparous women with term pregnancies with an unfavourable cervix (bishop 0 to 4 ) compared single (16F foley) and double balloon catheter and vaginal PGE2, showed that the single balloon catheter had the shortest induction to delivery interval (single balloon=25.8 hours). Heinemann et al systematic review of 30 RCTs showed an increased risk of both, maternal and neonatal infection when all (foley catheters, hygroscopic dilators, Laminaria) mechanical methods were analysed. ${ }^{8}$

Limited studies are available which compare the various, pharmacological and mechanical method of inducing labor within the same population. Hence the main objective of this study was to compare the four different methods of inducing labor: vaginal misoprostol, intracervical dinoprostone gel, foley catheter, extra amniotic saline infusion (EASI) along with vaginal misoprostol, in terms of efficacy, safety, maternal and fetal complications.

\section{METHODS}

This prospective, observational study was conducted on hundred patients admitted to labor ward of Sri Dharmasthala Manjunatheshwara College of Medical Sciences and Hospital, Dharwad for induction of labor during one-year period, from $1^{\text {st }}$ November 2016 to $30^{\text {th }}$ October 2017.

\section{Inclusion criteria}

The inclusion criteria were all primigravida with alive singleton pregnancy with cephalic presentation with poor bishops score and pregnancy (>/=40 weeks) who were not in labor.

\section{Exclusion criteria}

Pregnancy with complications such as IUGR, diabetes, hypertension, oligohydramnios and premature rupture of membrane were excluded from the study.

A total of hundred patients who fulfilled the inclusion criteria were selected from the four different methods of induction, with twenty-five in each group. The methods of induction being tab. misoprostol $25 \mu \mathrm{g}$ vaginally (PGE1) every 4 hours with maximum of 4 doses, intracervical dinoprostone gel (PGE2) every 6 hours with maximum of 3 doses, foley catheter intracervical until there was a spontaneous expulsion of the catheter or no longer than 24 hours and extra amniotic saline infusion along with tab. misoprostol $25 \mu \mathrm{g}$ vaginally every 4 hours with maximum of 4 doses. The catheter was kept in situ until there is spontaneous expulsion or no longer than 24 hours. Augmentation with oxytocin was done as per labor ward protocol. At first, the study method was completely explained to them and if the written consent was obtained, they were entered for the study. There were no interventions done in the study. The ethics committee of authors institution approved the study. The detailed history, examination, confirmation of diagnosis and investigations were recorded for all the participants. The groups were compared with respect to maternal age, bishops score, induction delivery interval, mode of 
delivery, post-delivery complications, Apgar score and NICU admission. Data was presented as mean and standard deviation and association among the study groups was done using one-way anova test chi-square test. Pair wise comparison was done using Tukeys multiple posthoc procedures.

\section{Statistical analysis}

Data was statistically analysed using SPSS 17 software. P values of less than 0.05 was taken as statistically significant.

\section{RESULTS}

There were 100 primigravida patients with Postdated pregnancy involved in this study with twenty-five in each method of induction, tab. misoprostol $25 \mu \mathrm{g}$ (PGE1) vaginally, dinoprostone gel (PGE2), Foley catheter and extra amniotic saline infusion (EASI) along with vaginal tab. misoprostol $25 \mu \mathrm{g}$. The groups were comparable with respect to the maternal age, bishops score, fetal weight. The mean maternal age was 25 years in PGE1 group, 26 years in PGE2 group, 23 years in foley group and 24 years in the EASI +misoprostol group. The mean bishop's score was 5.4 in misoprostol group, 5.3 in dinoprostone gel group, 5.5 in foley group and 5.4 in EASI +misoprostol group. With respect to the fetal weight in misoprostol group it was $2.66 \mathrm{~kg}$, while dinoprostone gel group it was $2.7 \mathrm{~kg}$, foley group was $2.71 \mathrm{~kg}$ and the EASI +misoprostol group had a weight of $2.77 \mathrm{~kg}$ (Table $1)$.

Among the hundred participants, patients who underwent vaginal delivery were 14 (56\%) in PGE1 group $15(60 \%)$ in PGE2 group, $13(52 \%)$ in foley group and $5(20 \%)$ in the EASI +misoprostol group. The mean Induction delivery interval was 19 hours in PGE1 group, 20 hours in PGE2 group, 25.79 hours in foley group and 25.14 hours in EASI +misoprostol group $(\mathrm{p}=0.0021)$. PGE1 group had a shorter induction delivery interval compared to foley group $(\mathrm{p}=0.0034)$ (Table 2). The patients requiring single dose of induction were $4 \%$ in misoprostol group in comparison to $44 \%$ in dinoprostone gel group (Table 3). On the other hand, women who underwent caesarean section were $10(40 \%)$ in the PGE1 group, $9(36 \%)$ in the PGE2 group $10(40 \%)$ in the foley group $18(72 \%)$ in the EASI +misoprostol group (Table 4). Vaginal delivery was highest in PGE2 group while caesarean section was highest in the EASI +misoprostol group $(\mathrm{p}=0.0372)$. The primary indication for caesarean section in misoprostol group was fetal distress (50\%) while dinoprostone group it was meconium stained liquor (55\%). Fetal distress was a common indication in Foley (70\%) and EASI +misoprostol group. The other indication for caesarean section was failed induction, seen in $20 \%$ of patients in misoprostol group and $10 \%$ in the EASI+ vaginal misoprostol group.

Table 1: Comparison with respect to age, bishop score and fetal weight.

\begin{tabular}{|llllll|}
\hline Variable & $\begin{array}{l}\text { Misoprostol 25 } \\
\text { Mg (PGE1) }\end{array}$ & $\begin{array}{l}\text { Dinoprostone } \\
\text { gel (PGE2) }\end{array}$ & Foley catheter & EASI +misoprostol 25 & P value \\
\hline Age & $25.40 \pm 3.86$ & $26.88 \pm 4.96$ & $23.88 \pm 3.36$ & $24.48 \pm 3.64$ & 0.0524 \\
\hline Bishop score & 5.40 & 5.32 & 5.56 & 5.44 & 0.8005 \\
\hline Fetal weight & 2.66 & 2.78 & 2.71 & 2.77 & 0.2439 \\
\hline
\end{tabular}

Table 2: Comparison with respect to induction delivery interval.

\begin{tabular}{|lll|}
\hline Groups & Mean & SD \\
\hline M 25 & 19.00 & 3.18 \\
\hline Dinoprostone gel & 20.94 & 6.38 \\
\hline Foley catheter & 25.79 & 4.68 \\
\hline EASI +M25 & 25.14 & 5.01 \\
\hline
\end{tabular}

$* \mathrm{P}=0.0021$.

Table 3: Comparison by the number of doses used for induction of labor.

\begin{tabular}{|lllll|}
\hline $\begin{array}{l}\text { Number of doses of } \\
\text { induction }\end{array}$ & $\begin{array}{l}\text { Misoprostol 25 } \\
\mu \mathrm{g}(\text { PGE1) } \boldsymbol{( \% )}\end{array}$ & $\begin{array}{l}\text { Dinoprostone gel } \\
(\text { PGE2) } \boldsymbol{( \% )}\end{array}$ & Foley catheter & $\begin{array}{l}\text { EASI +misoprostol } \\
\mathbf{2 5} \boldsymbol{\mu g}(\boldsymbol{\%})\end{array}$ \\
\hline One & 4 & 44 & - & 88 \\
\hline Two & 8 & 36 & - & 4 \\
\hline Three & 4 & 20 & - & 8 \\
\hline Four & 40 & 0 & - & 0 \\
\hline
\end{tabular}

Chi-square $=22.0355, \mathrm{p}=0.1069$. 
In respect to complications, $\mathrm{PPH}$ and blood transfusion was found to be more in the PGE1 group that is $2(8 \%)$ and $4(16 \%)$ respectively (Table 5). Patients with fever of 3 days duration was seen maximum with EASI + misoprostol group that is, $2(8 \%)$. Mean Apgar values at 1 minute 7.56 in PGE1 group, 7.44 in PGE2 group, 7.4 in foley group and 7.32 in EASI + misoprostol group $(\mathrm{p}=0.8070)$. The scores at 5 minutes was 8.24 in PGE1 group, 8.2 in PGE2 group 8.4 in foley group, 8.2 in EASI + misoprostol group $(\mathrm{p}=0.9020)$. There was not much difference between the groups (Table 6). Maximum period of NICU admission was seen with EASI +misoprostol group i.e., 10 days while least period was seen with PGE1 group i.e., 1 day (Table 7).

Table 4: Comparison with respect to method of delivery.

\begin{tabular}{|lllll|}
\hline Method of delivery & $\begin{array}{l}\text { Misoprostol 25 } \\
\mu g(\text { PGE1) }\end{array}$ & $\begin{array}{l}\text { Dinoprostone gel } \\
(\text { PGE2) }\end{array}$ & Foley catheter $(\%)$ & $\begin{array}{l}\text { EASI +misoprostol } \\
\mathbf{2 5} \boldsymbol{\mu g}(\boldsymbol{\%})\end{array}$ \\
\hline VD & 56 & 60 & 52 & 20 \\
\hline CS & 40 & 36 & 40 & 72 \\
\hline Instrumental & 4 & 4 & 8 & 8 \\
\hline
\end{tabular}

Chi-square $=8.4703, \mathrm{p}=0.0372 *$. P value $<0.05, \mathrm{CS}$ : Caesarean section, Instrumental-vacuum /forceps, VD: Vaginal delivery.

Table 5: Distribution of patients in four study groups by complications.

\begin{tabular}{|lllll|} 
Maternal complications & $\begin{array}{l}\text { Misoprostol 25 } \\
\mu g(\text { PGE1) }\end{array}$ & $\begin{array}{l}\text { Dinoprostone gel } \\
(\text { PGE2) }\end{array}$ & Foley catheter (\%) & $\begin{array}{l}\text { EASI +misoprostol } \\
\mathbf{2 5} \boldsymbol{\mu g}(\boldsymbol{\%})\end{array}$ \\
\hline PPH & 16 & 12 & 12 & 12 \\
\hline Fever & 4 & 4 & 4 & 8 \\
\hline Blood transfusion & 8 & 4 & 8 & 8 \\
\hline
\end{tabular}

Table 6: Comparison according to neonatal Apgar score at 1 and 5 minutes.

\begin{tabular}{|c|c|c|c|c|c|}
\hline Apgar score & $\begin{array}{l}\text { Misoprostol } 25 \\
\mu \mathrm{g} \text { (PGE1) (\%) }\end{array}$ & $\begin{array}{l}\text { Dinoprostone } \\
\text { gel (PGE2) }(\%)\end{array}$ & $\begin{array}{l}\text { Foley catheter } \\
(\%)\end{array}$ & $\begin{array}{l}\text { EASI +misoprostol } 25 \\
\mu \mathrm{g}(\%)\end{array}$ & P value \\
\hline 1 minute & 7.56 & 7.44 & 7.40 & 7.32 & 0.8070 \\
\hline 5 minutes & 8.24 & 8.2 & 8.4 & 8.28 & 0.9020 \\
\hline
\end{tabular}

$* \mathrm{P}$ value $<0.05$.

Table 7: Distribution of patients in four study groups by NICU status.

\begin{tabular}{|c|c|c|c|c|}
\hline NICU admission & $\begin{array}{l}\text { Misoprostol } 25 \\
\text { g (PGE1) }(\%)\end{array}$ & $\begin{array}{l}\text { Dinoprostone gel } \\
\text { (PGE2) }(\%)\end{array}$ & Foley catheter (\%) & $\begin{array}{l}\text { EASI+misoprostol } 25 \\
\mu \mathrm{g}(\%)\end{array}$ \\
\hline 1 day & 8 & 4 & 4 & 0 \\
\hline 2 days & 4 & 0 & 0 & 0 \\
\hline 3 days & 4 & 16 & 12 & 8 \\
\hline 5 days & 4 & 4 & 0 & 12 \\
\hline 7 days & 0 & 0 & 4 & 0 \\
\hline 10 days & 0 & 0 & 0 & 8 \\
\hline
\end{tabular}

\section{DISCUSSION}

In this study, a total of 100 pregnant women with indication for pregnancy termination were evaluated. There were 4 groups that were studied that is vaginal misoprostol (PGE1), intracervical dinoprostone gel (PGE2), foley catheter, extra amniotic saline infusion (EASI) +vaginal misoprostol. This study was conducted in Sri Dharmasthala Manjunatheswara College of Medical Sciences and Hospital, Dharwad for a study period of one year. The studied groups were almost similar in the view of demographic characteristics including age, number of ANC visits, gestational age, parity, and bishop score.

Maternal outcome was assessed in terms of BIshop's score, induction delivery interval, and mode of delivery and complications. In term of Induction delivery interval significant difference was observed between groups vaginal misoprostol and foley catheter $(p=0.0034)$ that was similar to a study done by Roudsari et al which showed that the mean time to delivery was significantly 
shorter in misoprostol group rather than the Foley catheter group. ${ }^{9}$ Misoprostol had the shortest Induction delivery interval in contrast to study by Calder et al and Reinhard et al which concluded that a single application of PGE2 gel caused favorable changes in the cervix by increasing the bishop score and shortened the induction delivery interval. ${ }^{10,11}$

In this study vaginal delivery was highest in the PGE2 group while cesarean section was highest in the EASI + misoprostol group, in contrast to a study by Jozwiak et al. concluded that induction of labor using mechanical methods results in similar cesarean section rates as prostaglandins. $^{12}$

A significant difference was observed between no of doses of induction between PGE1 and PGE2 group but among others, no much difference observed, due to other induction methods that were combined with each method, which was one of the few drawbacks of the study. PPH, fever and blood transfusion were some of the complications that were seen between the groups. Post op fever was seen maximum with the EASI + misoprostol group probably due to nosocomial infection. PPH and blood transfusion was seen maximum in PGE1 group. There were no major complications in this study.

Neonatal outcome was assessed in terms of the Apgar score at 1 and 5 minutes of life and NICU admissions. Apgar score was comparable between the study populations. Neonatal complications such as meconium aspiration, grunting, weak cry, birth weight was noted and required NICU admissions. However, no mortality was observed in the study population. There was no much difference in respect to the fetal birth weight. NICU admission was seen maximum with the EASI + misoprostol group and minimum with PGE1 alone.

\section{CONCLUSION}

In the present study, characteristics such as age, parity, gestational age, bishop score were comparable between the four groups. The shortest Induction delivery interval was seen with vaginal misoprostol alone in comparison to others. Maximum number of patients under PGE2 group had vaginal delivery and highest caesarean section rate was seen with EASI + misoprostol induction group. NICU admission was maximally seen with EASI + misoprostol group mainly due to meconium stained amniotic fluid and fetal respiratory distress. There was no maternal and neonatal mortality observed in the study population.
Funding: No funding sources

Conflict of interest: None declared

Ethical approval: The study was approved by the Institutional Ethics Committee

\section{REFERENCES}

1. De Ribes C. De l'Accouchementrovoque, Dilatation du Canal Genital a l'Aide deBallons Introduitsdans la Cavite Uterine Pendant la Grossesse. Paris, Steinheil; 1988.

2. Cunningham, Gary F, editor. Williams Obsterics. $24^{\text {th }}$ edition, Bloom SL, Spong CY, Dashe JS, Hoffman BL, Casey BM, et al, New York: McGraw-Hill Education/Medical; 2014.

3. Eden TW. Review: a manual of midwifery, $3^{\text {rd }}$ ed. Lancet. 1912;1:1064.

4. Page EW. Response of human pregnant uterus to pitocintannate in oil. Proc Soc Exp Biol. 1943;52:195-7.

5. Karim SMM, Trussele RR, Patel RC, Hillier K. Response of pregnant human uterus to prostaglandin F2 alpha induction of labour. BMJ. 1968;IV:621-3.

6. Keirse MJNC. Prostaglandins in pre-induction cervical ripening. Meta-analysis of world-wide clinical experience. J Reprod Med. 1993;38(Suppl):69-98.

7. Wing DA. Misoprostol vaginal insert compared with dinoprostone vaginal insert: a randomized controlled trial. Obstet Gynecol. 2008;112(4):801-12.

8. Atad J, Bornstein J, Calderon I, Petrikovsky BM, Sorokin Y, Abramovici H. Nonpharmaceutical ripening of the unfavorable cervix and induction of labor by a novel double balloon device. ObstetGynecol. 1991;77:146-52.

9. Roudsari FV, Ayati S, Ghasemi M, Mofrad MH, Shakeri MT, Farshidi F, et al. Comparison of vaginal misoprostol with foley catheter for cervical ripening and induction of labor. Iran $\mathbf{J}$ Pharm Res. 2011;10(1):149-54

10. Calder AA, Embrey MP, Tait T. Ripening of the cervix with extra-amniotic PGE2 in viscous gel before induction of labor. Br J Obstet Gynaecol. 1977;84:2648.

11. Reinhard J, Raddatz R, Langer R, Fessler S, Kaufmann C, Nteli VA, et al. Pilot study. Mechanical versus pharmacological term induction: a cohort group analysis of maternal and neonatal outcome-hygroscopic cervical dilator versus prostaglandin E2. Clin Obstet Gynecol Reprod Med. 2016;2.

12. Jozwiak M, Bloemenkamp KW, Kelly AJ, Mol BW, Irion $\mathrm{O}$, Boulvain $\mathrm{M}$. Mechanical methods for induction of labour. Cochrane Database of Syst Rev. 2012;3:Art.No:CD001233.

Cite this article as: Shetty EM, Neravi A. A

comparative study of vaginal misoprostol, dinoprostone gel, foley catheter, extra amniotic saline infusion along with vaginal misoprostol for induction of labor at term. Int J Reprod Contracept Obstet Gynecol 2020;9:3683-7. 